\title{
ON THE MEANING OF THE PREPONDERANCE TEST IN JUDICIAL REGULATION OF CHEMICAL HAZARD*
}

\author{
TALBot Page $\dagger$
}

I

\section{INTRODUCTION}

Posner suggests in his Economic Analysis of Law ${ }^{1}$ that the criterion of economic efficiency provides a basis for burden of proof rules, and, in particular, a basis for the preponderance test. This paper also examines the preponderance test in light of the criterion of economic efficiency, but with somewhat different results.

The example and focus here is on the appropriate control of chemical hazards; or, more precisely, the design of burden of pronf rules with appropriate incentives, stemming from past decisions, for future precautionary controls in similar cases. The analysis is sufficiently general to apply to other rules besides the preponderance test, such as 'clear and convincing evidence' and 'beyond a reasonable doubt,' and to apply to other problems besides chemicals.

This article assumes that general regulatory frameworks-judicial, legislative, or administrative - are in place and that their chief purpose is to maximize the social benefits, or minimize the social costs, of the substance or activity under consideration as a candidate for regulation. In any given case, cost minimization might call for doing nothing - not finding liability or leaving a chemical unregulated because its benefits exceed its costs, and what costs there are could only be avoided at undue expense; cost minimization might call for finding liability or for regulating a chemical in some way and to some degree because a carefully designed regulation will yield benefits net of regulatory costs; or cost minimization might call for banning a chemical because it has no benefits or because its benefits are smaller than adverse effects that could be avoided only by foregoing use of the chemical.

There is no great difficulty in choosing among these alternatives if all relevant costs and benefits are known; there is considerable difficulty, however, if the relevant costs and benefits are not known. And, in the case of chemical hazards and related risks, benefits and costs are typically uncertain. For example, one might be

Copyright $(\mathcal{C} 1983$ by Law and Contemporary Problems

* Research for this article was supported by the National Science Foundation and the Mellon Foundation. The article also owes much to Jim Krier who generously contributed much of the first two sections.

$\dagger$ Senior Research Associate, Environmental Quality Laboratory, California Institute of Technology.

1. R. Posner, Economic Analysis of Law 432 (2d ed. 1977). 
sure of the direct costs of manufacturing and controlling a given chemical, of the good things the chemical can do for us, and of the probability that it will do those things. On the other hand, one will commonly be unsure of the range of possible adverse effects the chemical might entail and of the probability that any of those effects will in fact occur. Hence, subjective judgments about uncertainty are necessary, and the chief concern here is the rules - of burden of proof-by which these judgments should be made.

Explored here are some implications of a simple criterion-that burden of proof rules should be designed to minimize the expected costs of the decision process. More specifically, this article will focus on the implication that for expected costs to be minimized, the standard of proof must vary with the hazards in question. This proposition has consequences for a wide range of contemporary problems-of which synthetic chemicals is but one example.

\section{The Conventional and Economic Wisdom}

The first step is to consider judicial regulation of hazards through such substantive common law rules as strict liability, negligence, and nuisance. The starting point is with the courts and the common law, not because these are the best institutions for controlling the problems which will be discussed, but because it is in judicial common law decisions (and the literature about them) that one finds the most explicit and canonical recognition of various burden of proof rules.

First, assume there is a substantive standard of strict liability on the part of producers of a certain chemical for any injuries the chemical happens to cause. For purposes here, strict liability means liability whether or not the producer is careless. In other words, the fact that measures to reduce the hazards of the chemical (including foregoing its production) would cost more than the increased safety resulting from the measures is irrelevant; ${ }^{2}$ if the chemical did in fact cause the injury, its producer is accountable.

Turn now from a strict liability regime to a regime based on negligence (or on related substantive doctrines, such as nuisance, that incorporate a standard of reasonableness). In one view-an economic one-negligence, nuisance, and other rules of reason are designed to promote cost minimization. Judge Learned Hand's definition of negligence, set out in United States $v$. Carroll Towing Co., ${ }^{3}$ illustrates the proposition: negligence exists when the cost of an accident multiplied by the probability of the accident's occurring exceeds the cost of measures the injurer could have taken to avoid the accident. ${ }^{4}$ This version of the negligence standard aims to minimize costs by deterring activities in all those cases (but only those cases) when the activities give rise to expected costs larger than the costs of avoidance.

2. Irrelevant for the particular case, but under an economic efficiency approach these costs are relevant to the decision whether to impose a strict liability or a negligence rule in similar cases.

3. 159 F.2d 169 (2d Cir. 1947).

4. Id. at 173 . 
As stated previously, there is no great difficulty in choosing an efficient decision if all relevant costs and benefits are known. Simlarly, there is no great difficulty in applying a strict liability or negligence or nuisance standard if one knows the relevant facts. In the case of strict liability, this means knowing that an injury occurred, knowing that the defendant's activity caused it, and knowing what damage resulted. In the case of negligence, this means knowing - in addition - the defendant's avoidance cost, the cost of injuries of the sort threatened by the defendant's activity, and the probability that the threat will be realized. Typically, of course, some or all of these elements are contested (uncertain), such that the trier of fact must, based on the evidence presented, make a guess as to the true state of affairs. But these guesses are not made in the abstract; burden of proof standards establish and allocate the risk of uncertainty by determining who wins if the factfinder is undecided, and by determining what "undecided" means (a judge may find evidence convincing if the applicable standard of conviction is low, but unconvincing if it is high). In ordinary civil cases like those so far discussed, the plaintiff bears the burden of persuasion (that is, the risk of indecision is allocated to him), and he carries this burden only if he can convince the factfinder that his version of the facts is supported by a preponderance of evidence. This requirement is generally taken to mean that the plaintiff must show that the assertions on which his case turns are more likely true than not true.

The traditional interpretation of this standard in a strict liability regime is that the plaintiff must convince the court that the probability that the defendant's activity caused the plantiff's injury, to the extent of $\$ \mathrm{X}$, is more than $50 \%$. If the plaintiff does not convince the court that the probability is greater than $50 \%$, the preponderance test implies that the plaintiff loses. The negligence case is more complicated, partly because one has to deal with probabilities of probabilities. According to the Hand formula, negligence liability turns on a comparison of the defendant's avoidance cost to the expected cost of an accident. To make out a case the plaintiff must, in principle, prove not only all the "facts" required under strict liability (identity of the injurer, cause and effect relationship, extent of injury) but also the additional "facts" regarding defendant's avoidance cost, the cost of an accident of the sort threatened, and the probability that such an accident would result from the defendant's operation. The preponderance test requires that the plaintiff's evidence must convince the factfinder that the expected accident cost is sufficiently high, relative to the defendant's avoidance cost, to establish negligence. This does not mean that the probability of an accident must exceed 50\%. Suppose, for example, that the plaintiff proves by a preponderance of the evidence that the defendant engaged in an operation that injured the plaintiff, that defendant's avoidance cost was $\$ 1000$, and that the gravity of the threatened harm was $\$ 5000$. To win his case (contributory negligence aside), the plaintiff must also convince the judge that the probability of injury exceeded $20 \%$ without the defendant's precautionary actions and so the expected accident cost would exceed the defendant's avoidance cost. One possible interpretation of the preponderance test-an interpretation to be explored in this article-is that "convince" means to show that a greater than $20 \%$ probability is more likely true than not, and the plaintiff wins if 
the factfinder concludes from the evidence that the probability of the $20 \%$ figure being "true" or "accurate" or a "fact" exceeds $50 \%$.

The foregoing represents the conventional wisdom-to the extent there is agreement on a conventional view at all-regarding the burden of proof (more particularly, the burden of persuasion) in ordinary civil litigation. Thus, a standard treatise on evidence states that in such cases-a suit in tort for personal injuries, say- "the party who has the burden of pleading a fact will have the burdens of producing evidence and of persuading the jury of its existence as well." 5 The party carries the burden of persuasion of a fact by proving it " by a preponderance of evidence," " which by its "most acceptable meaning . . . seems to be proof which leads the jury to find that the existence of the contested fact is more probable than its nonexistence."6 Under this conventional view "a lawsuit is essentially a search for probabilities. A margin of error must be anticipated in any such search. Mistakes will be made, and in a civil case a mistaken judgment for the plaintiff is no worse than a mistaken judgment for the defendant."7

There is marked congruity between the foregoing and Posner's view regarding burden of proof. In his treatise Economic Analysis of Law, Posner considers the preponderance of the evidence standard that governs civil cases.

[1] This standard directs the trier of facts to find in favor of the party who has the burden of proof on an issue if that party's version of the disputed facts is more probably true than the other party's version; thus, to prevail, the party bearing the burden of proof need only establish the validity of his claim by a probability infinitesimally greater than 50 percent. [2] This implies that of cases decided erroneously, about half will be won by undeserving plaintiffs and about half lost by deserving plaintiffs.

[3] Whether this result is economically sound depends on whether the costs of each type of error-in favor of undeserving plaintiffs, and

[4]against deserving plaintiffs-are about the same; and in general it would seem that they are the same. ${ }^{8}$

As the last line of this quotation suggests, the preponderance test is justified, in the economic view, as a cost-minimizing measure (with regard to the costs of error in particular). Posner makes this point slightly more explicit in another work. ${ }^{9}$ Perhaps surprisingly, conventional writers appear to agree with this view, at least in part; the language of "cost minimization" might be foreign to them, but the idea is reflected in McCormick's observation, quoted above, that "in a civil case a mistaken judgment for the plaintiff is no worse than a mistaken judgment for the defendant." With the presumption of equal error costs in either direction, the correct approach in terms of minimizing those costs appears to be a standard of proof favoring neither side while still serving the necessary function of resolving cases when the mind of the factfinder is in equipoise. The preponderance test is precisely such a standard.

Why should cases be resolved in favor of the defendant when the factfinder is

5. MCCORMiCK's HANDBOOK OF THE LAW OF Evidence $§ 337$, at 785 (E. Cleary 2d ed. 1972).

6. Id. $\S 339$. This definition of the preponderance test will be referred to as "Point 1" below.

7. Id. $\S 341$. The claim that the costs of the two errors are the same will be referred to as "Point 3 " below.

8. R. POSNER, supra note 1 , at 432 .

9. R. Posner, An Economic Approach to Legal Procedure and Judicial Administration, J. LEGAL. STUDIES, June 1973 , at $399,408-10$. 
in equipoise? Here it is difficult to judge the degree of agreement between the economic and the conventional views. Posner's answer is straightforwardly concerned with efficiency: "since no allocative purpose would be served by shifting a loss in a case where the defendant's liability was indeterminate, the rule [placing the risk of nonpersuasion on the plaintiff] economizes on litigation expenditures." 10 Or, as Posner puts it elsewhere, "an error in plaintiff's favor involves a cost not incurred when the error goes the other way-the cost of actually collecting a legal judgment."11

Perhaps conventional analysts like McCormick mean the same thing when they say that the "burdens of pleading and proof with regard to most facts have been and should be assigned to the plaintiff who generally seeks to change the present state of affairs and who therefore naturally should be expected to bear the risk of failure of proof or persuasion." 12 Other factors conventionally mentioned as bearing on allocation of the risk of nonpersuasion are obscure "policies" of various sorts-handicapping disfavored contentions, convenience in following the natural order of storytelling, consideration of which party has readier access to knowledge about the fact in question, consideration of the extent to which a party's contention departs from what would be expected in the course of ordinary experience (the more unusual the claim, the more likely the proponent will have to prove it), and, finally, a catchall of "fairness." 13 Each of these factors could be construed as consistent with the economic view, or inconsistent. The obscurity of these factors defies generalization along these lines, as does the fact that none of the factors governs regularly. James and Hazard conclude that "[ $\mathrm{t}]$ here is no satisfactory test for allocating the burden of proof . . . ."14 Posner, as well as this author, would argue that there is-if the objective is cost minimization.

\section{POINTS AT IsSuE}

There appear to be several problems of interpretation or points of confusion in the conventional wisdom.

First, (Point 1) both McCormick and Posner provide a fairly clear definition of the preponderance standard itself. Posner states, as quoted above, that the preponderance test "directs the trier of facts to find in favor of the party who has the burden of proof on an issue if that party's version of the disputed facts is more probably true than the other party's version." 15 It is not altogether clear, however, what this definition means when the "fact" is a disputed probability. The diffi-

10. Id. at 408 .

11. R. POSNER, supra note 1 , at 433 .

12. MCCORMICK'S HANDBOOK OF THE LAW OF EVIDENCE, supra note $5, \S 337$, at 786 (emphasis added).

13. Id. at $786-89$.

14. F. James \& G. Hazard, Civil Procedure $§ 7.8$, at 249 (2d ed. 1977).

15. MCCORMICK'S HANDBOOK OF THE LAW OF EvIDENCE, supra note 5, says much the same thing. See also California SuPERIOR COURT (LOS ANGeles Co.) COMMITTEe ON STANDARD JuRy InSTRUCtions, Civil, California Jury InStructions Civil $\$ 2.60$ (6th ed. 1977). 
culty here is not so much in the definition but in its application to probabilities of probabilities.

Second, (Point 2) Posner states "that of the cases decided erroneously, about half will be won by undeserving plaintiffs and about half lost by deserving plaintiffs." 16

Third, (Point 3) both McCormick ${ }^{17}$ and Posner state that the costs of the two types of error are about the same.

Fourth, (Point 4) Posner states that a necessary condition for the preponderance test to be economically sound (we take this to mean minimizing expected cost) is that the costs of the two types of error be about the same.

The last three statements are about error. Ironically, the statements themselves appear to be erroneous. Unraveling the confusions suggests a new, and more economically sound, interpretation of the preponderance test. The interpretation will be developed in principle. James and Hazard observe in a slightly different context, burden of proof tests "formulated in terms that suggest objective, scientific precision" are in practice not so precise. ${ }^{18}$ Precision in principle, useful in clarifying ideas, must usually be translated into something less definite but more operational in practice. Still, the different standards regarding the required degree of conviction of the part of a decisionmaker "probably suffice" to create "a frame of mind to resist persuasion" to a roughly appropriate extent, "and it is doubtful whether anything more can be done where a difference in degree is sought in dealing with factors so subjective and imponderable."19

\section{IV}

\section{SOCIAL COSTS}

The key to the argument lies in the distinction between the private costs in a single negligence case and the social costs associated with a particular standard of proof. The distinction is easiest to draw in terms of a specific example.

Suppose a woman takes an antinausea drug during pregnancy and her child is born without arms. She believes that the drug was teratogenic and sues the drug manufacturer for $\$ 1$ million. To make matters simple, assume that the defendant stipulates that $\$ 1$ million is a good estimate of the pain and suffering, lost income, etc., associated with the teratogenic effect, but argues that its drug was not the cause of the effect.

If the chemical is teratogenic and the plaintiff is deserving, but liability is not found, the private cost of this judicial error is $\$ 1$ million to the plaintiff. If the chemical is not teratogenic and the plaintiff is undeserving, but liability is found, the private cost of this judicial error is $\$ 1$ million to the defendant. Thus, it would seem that the costs of the two types of error are the same as affirmed by McCormick and Posner.

16. See supra text accompanying note 8 .

17. See supra text accompanying note 7.

18. F. JAMES \& G. HAZARD, supra note $14, \S 7.11$, at 273.

19. Id. $\$ 7.6$, at 245 . 
These error costs, however, have to do with a private transfer, which may or may not occur between the defendant and the plaintiff. They relate to a decision already made (the decision to produce and market the drug) and a harm already sustained. As such, these error costs have little to do with economic efficiency or cost minimization. Economic efficiency focuses upon the consequences of future decisions which are affected by the precedent in today's particular case.

Suppose that liability is found in this particular case. The result is an incentive for manufacturers not to produce or to restrict drugs in future but otherwise similar situations when the evidence of toxicity is equally strong and the costs and benefits are about the same as in the case at hand. If liability is found for the particular case at hand, then society is likely to forego the benefits of drugs with similar benefits and risks in the future.

Suppose that liability is not found in this particular case. The result is an incentive for manufacturers to produce drugs in future but otherwise similar situations when the evidence of toxicity is equally strong and the costs and benefits are about the same as in the case at hand. If liability is not found for the particular case at hand, then society is likely to bear the risks of drugs with similar benefits and risks in the future.

In the hypothesized case there has been identified only a single victim with a cost of $\$ 1$ million, the cost which may or may not have been caused by the drug. This $\$ 1$ million is, however, only part of the relevant cost comparison for cost minimization. There may be 1000 or 10,000 other victims, and this number is also relevant for a decision which attempts to minimize social costs. To be concrete, suppose that in the particular example, and in similar cases, there are an estimated 1000 victims, each suffering $\$ 1$ million in damages, for a total cost of $\$ 1$ billion. This total is cost $C$.

On the other side of the ledger, the chemical conveys benefits in the form of relief from nausea. Assume that 10 million women take the drug, and the relief from nausea is valued at $\$ 30$ over and above the manufacturing, distributing, and retailing costs of the drug. ${ }^{20}$ The total benefit-net production cost-is $\$ 30$ times 10 million or $\$ 300$ million. This total is net social benefit $B$.

This $\$ 300$ million is also what Hand called the avoidance cost. If liability is found in this case, then in similar cases manufacturers can avoid the risk of teratogenicity by not manufacturing the similarly suspected drugs. The cost of such avoidance is net social benefit foregone-the $\$ 300$ million. The costs of manufacturing, distributing, and retailing are transfers which are netted out in the analysis of net social cost minimization.

This analysis permits one to consider the expected cost-minimizing standard of proof. Suppose that the court weighs the evidence brought forward by both plaintiff and defendant and concludes that the probability of teratogenicity is $p$. If the court finds liability, it knows that in this case and in similar cases drugs will not be manufactured. (In similar cases the weight of evidence of toxicity will be about

20. The prescription might cost a woman $\$ 20$, but she obtains nausea relief which she values at $\$ 50$. This $\$ 30$ net benefit is also valued as the benefit over and above the next best alternative treatment for the nausea. 
the same.) For each such situation there will be no benefits, but at the same time no toxic effects of the drugs. With the zero net benefit from nonmanufacture as the benchmark, one can compare the effects of the other possible decision, which is a finding of nonliability. With a finding of nonliability in this case, drugs will be manufactured in similar situations. For such cases the benefit is $B$ and the expected cost is $p C$. When $p C$ is greater than $B$, there are net expected costs of manufacturing, and society will minimize future costs by future precautionary decisions of nonmanufacture. This result is achieved by sending the signal of a finding of liability in the case at hand. When $p C$ is less than $B$ there are net expected benefits for the drugs, and compared with the zero benefit benchmark of nonmanufacture, society will do better with the nonprecautionary decision encouraging manufacture. This result is achieved by sending the signal of finding no liability in the case at hand.

Note that $p C$ is greater than $B$ just when $p$ is greater than $B / C$. Thus the costminimizing standard of proof tells a decisionmaker to find liability when the court decides that the probability of teratogenicity is greater than $B / C$ and to find no liability when the probability is less than $B / C$. This standard of proof is the same as that proposed by Learned Hand, with the language recast in terms of toxic torts: negligence exists when the cost of the toxicity multiplied by the probability that the chemical is toxic exceeds the benefits of the chemical (or the avoidance costs of the manufacturer).

In the example, $B$ is $\$ 300$ million and $C$ is $\$ 1$ billion. Thus $B / C$ is 0.3 and the cost-minimizing standard of proof is to find liability if the court concludes that the probability of teratogenicity is greater than 0.3 . Restating the matter-the costs being minimized are not those of the present case at hand. For this case, the decision to manufacture is already taken and the injury (whether or not caused by the drug) already sustained. The costs to be minimized are those associated with future decisions of whether or not to manufacture drugs with similar benefits and similar suspicion of toxic risk. Note that "similar" need not be restricted to situations where $B$ is $\$ 300$ million and $C$ is $\$ 1$ billion. The standard of proof of 0.3 applies for any situation where the ratio of $B$ to $C$ is 0.3 . In other words, the precedent of the 0.3 standard of proof in this case should apply to all future cases where the ratio of $B$ to $C$ is 0.3 .

The error costs, from the social point of view, are as follows. If liability is found when in fact the chemical is nontoxic, the chemical is erroneously withdrawn from the market and its benefits erroneously foregone. This type of judicial error is a false positive. The cost of this false positive is $B$, or $\$ 300$ million in the example. If liability is not found when it is appropriate, and the chemical is toxic, the chemical is erroneously left on the market. ${ }^{21}$ The toxicity costs occur but its benefits are obtained as well. This type of judicial error is a false negative. The cost of this false negative is $C-B$, or $\$ 700$ million in the example.

As seen in the example, when the relevant costs of error are identified-the

21. Note that if $B$ is greater than $C$ the cost-minimizing decision is not to find liability even if it is known for sure that the drug is teratogenic. Thus, it may, in some cases, be appropriate not to find liability for a known teratogen. 
social costs in similar problems-the costs of the two types of error are not in general equal. They are only equal when $C$ happens to be twice $B$, a circumstance which must be viewed as exceptional. This is the argument against Point 3.

It is important to observe that minimizing expected costs of future decisions which are affected by the precedent of the case at hand is the same as minimizing the present expected error costs. Recall that the cost of a false positive is $B$, the cost of a false negative is $C-B$, and the court's evaluation of the probability of toxicity is $p$. If the court finds liability, it risks the possible error of a false positive. Since the court's evaluation of the probability of teratogenicity is $p$, the probability of nonteratogenicity is $(1-p)$. Therefore, if the court finds liability, the expected cost of a false positive is $(1-p) B$.

If the court does not find liability, it risks the possible error of a false negative with an expected cost of $(p)(C-B)$. To minimize the expected cost of error, the court should find liability when the expected cost of a false negative is larger than the expected cost of a false postive - when $(p)(C-B)>(1-p)(\mathrm{B})$ - and choose to find no liability when the expected cost of a false positive is greater than the expected cost of a false negative. Since $(p)(C-B)>(1-p)(B)$ exactly when $p>$ $B / C$, the future and present cost minimization criteria are basically the same.

Under the cost-minimizing standard of proof, liability should be imposed when the court finds that the probability of teratogenicity, $p$, is greater than $B / C$. In the exceptional circumstance, when the social error costs are equal, $C-B=B$, or $C=$ $2 B$, and the cost-minimizing standard becomes: impose liability when the court finds that the probability of teratogenicity is greater than $B / 2 B$ or $1 / 2$. This standard is simply the preponderance test applied to two conflicting factual claims: the plaintiff claiming that the drug is a teratogen and the defendant claiming that the drug is not a teratogen. If the only contested fact is whether or not the drug is a teratogen, and the court imposes liability based on a determination that the plaintiff's version of the fact is more likely true than not, the court's standard of proof is $p>1 / 2$.

It is not altogether clear why Posner and McCormick concluded that, in general, the error costs are equal, nor is it clear why Posner believed that the error costs must be equal for the preponderance test to be "economically sound." The above analysis, however, suggests a possible explanation for these views. One may easily confuse the relevant social costs of errors with the private costs of transfers between defendant and plaintiff. Since the private error costs are equal (both $\$ 1$ million in the example), such confusion would explain the assertion that the relevant social costs of error are equal. Once the error costs are believed equal, one can easily interpret the preponderance test as saying: find liability when the court concludes that it is more likely than not that the chemical is toxic $(p>B / C$, or $p>$ $1 / 2$ ). And once this (erroneous) interpretation of the preponderance test is accepted, it follows that for the preponderance test to be cost-minimizing, the error costs must be the same.

This whole rationale unravels once the proper distinction between private and social costs is made. When this distinction is made, the relevant error costs are not in general the same, and the cost-minimizing standard of proof is $p>B / C$. But 
then what about the preponderance test? Where does this notion "more likely than not" fit in? The distinction between private and social costs leaves open the question of how to interpret the preponderance test and relate it to cost minimization.

\section{Probabilities of Probabilities}

There are several ways of interpreting the preponderance test. In the preceding example, the plaintiff might assert as a fact that the drug is a teratogen and the defendant might assert as a fact that the drug is not a teratogen. Suppose that the court finds that the weight of evidence on either side is nearly balanced but that the defendant's version is slightly more credible than the plaintiff's. An obvious interpretation of the preponderance test would be for the court to conclude that since the defendant's version is more probable than the plaintiff's, there should be no liability.

However, this interpretation is inconsistent with cost minimization. Suppose, for example, in concluding that the evidence from both sides is balanced almost but slightly favors the defendant, the court decides the probability that the drug is teratogenic is about 0.45 . Since 0.45 is greater than 0.30 , the appropriate precedent for minimizing expected costs is to impose liability in the case at hand.

For another interpretation of the preponderance test, return to the exmaple, but suppose that neither side claims certainty. Instead of claiming that she knows for a fact that the drug is a teratogen, the plaintiff argues that the evidence points toward a conclusion that the drug is a teratogen. She argues that, although there are still some scientific doubts, a reasonable person would conclude there is an $80 \%$ probability that the drug is a teratogen. Likewise, the defendant does not claim as a fact that the drug is not a teratogen and admits that there is some evidence which suggests a slight probability of teratogenicity. According to the defendant, a reasonable person would conclude that there is only a $20 \%$ chance of teratogenicity. Again, assume that the court finds the arguments supporting these conflicting probabilistic evaluations to be almost equally balanced with the defendant's argument slightly more credible. Here the defendant's version of the "facts" is that the evidence of toxicity leads a reasonable person to conclude the probability is $20 \%$. The plaintiff's version of the facts is that the evidence leads a reasonable person to conclude the probability is $80 \%$.

The second interpretation of the preponderance test would be to decide that since the court found the defendant's version to be more probable, the court should accept his version. Thus, the court would conclude that the probability of teratogenicity is $20 \%$. Since 0.2 is less than the 0.3 required standard of proof, the court would find no liability under this interpretation.

This second interpretation of the preponderance test is also inconsistent with expected cost minimization. The problem is that the court is acting as though the defendant was entirely right and the plaintiff entirely wrong in their probability assessments. But in the court's own view both assessments have weight, nearly equal weight. Thus, in the court's own judgment the probability is not 0.2 (the 
defendant's claim) but something in between the defendant's 0.2 and the plaintiff's 0.8 . With nearly equal weight found in each assessment, the court's own judgment of probability will be closer to 0.5 (the average of 0.2 and 0.8 ) than the defendant's version of 0.2 . Suppose that after weighing the two probabilistic assessments the court decides the probability that the drug is teratogenic is 0.45 . Just as in the first interpretation, since 0.45 is greater than 0.30 , the appropriate precedent for minimizing expected costs in future cases is to impose liability in the case at hand.

Having rejected two possible interpretations of the preponderance test, the goal remains of finding an interpretation which is consistent with expected cost minimization and retains the concept of "something more likely than not." This objective may be reached by using a concept found in design theory: second order probabilities, or probabilities of probabilities. In the first interpretation, the litigants asserted full knowledge about the toxicity of the drug-the plaintiff asserting that she knew for a fact that the drug is teratogenic and the defendant asserting that he knew for a fact that it was not. In the second interpretation, the litigants were a little more humble. They agreed that they did not know for a fact whether or not the drug is a teratogen. Instead each weighed the existing evidence and came up with probability judgments. The plaintiff argued that the probability of teratogenicity was, in fact, 0.8 , and the defendant argued the probability was, in fact, 0.2. In the third (and final) interpretation, the litigants will be viewed as yet a little more humble.

The plaintiff's pleading is imagined as follows. She agrees that the evidence of toxicity is uncertain and that reasonable people could differ in its interpretation. She still argues that a reasonable person would assess the evidence as about a 0.8 probability of teratogenicity, but she admits some uncertainty as to this precise estimate. She expresses her uncertainty by "a judgmental probability distribution" (Figure 1(a)). This judgmental probability allows the plaintiff to state her uncertainty about her probability estimate. ${ }^{22}$ If her judgment had been very concentrated around the value of 0.8 (like a spike centered on 0.8 , as in Figure 1(b)), this would mean that she was claiming strong knowledge in her estimate of 0.8 . If her judgment had been more spread out (as in Figure 1 (c)), this would mean that she was more uncertain in her probability estimate.

Similarly, the defendant also admits that he is not certain that the probability of teratogenicity is only 0.2 . He too, especially under cross examination, is willing to express some uncertainty about his probability estimate of 0.2 . He does this in the form of his own judgmental probability distribution (Figure 2). His judgment is a little more spread out than the plaintiff's, because he admits to a little more uncertainty about his estimate.

After weighing the evidence brought forward by the two parties, the court forms its own judgment as to the probability of teratogenicity. The court also feels some uncertainty as to its probability judgment and expresses its uncertainty by its own judgmental probability distribution (Figure 3(a)). As before, the court's judg-

22. The judgmental probability distribution is a second order probability distribution which places probability weight where the probability assessor thinks the probability of toxicity is located. 
ment is between the versions of the two parties, and its judgment depends on the relative credibilities of the litigants. But, this time the court expresses its uncertainty as to the precise value of the probability.

\section{Probabilities of Probabilities as Represented by}

Second Order Probabilities

Figure 1

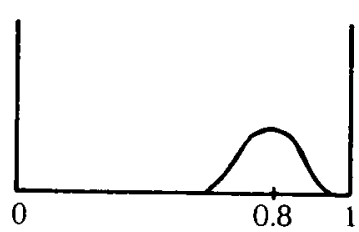

(a)

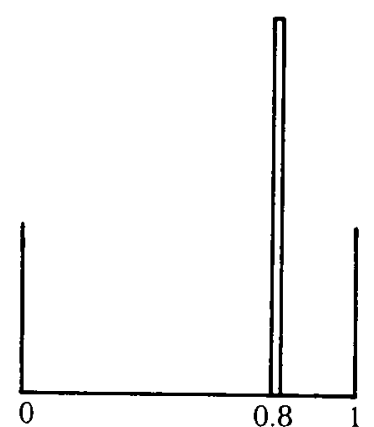

(b)

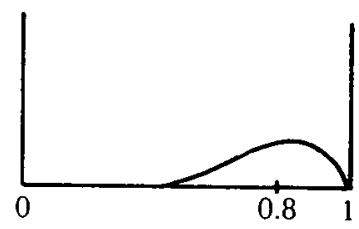

(c)

Figure 2

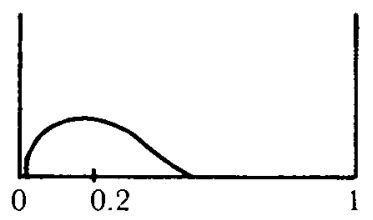

Figure 3

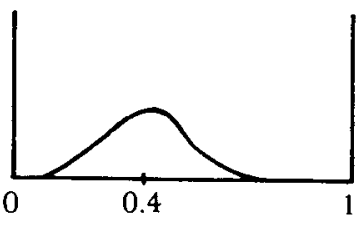

(a)

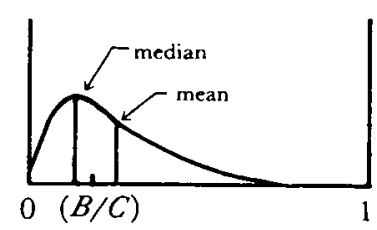

(b)

Following the criterion of expected cost minimization, the court should impose liability if this assessment of the expected costs is higher than the benefits. But how can the expected costs be assessed when the uncertainties are framed in terms of second order probabilities? One of the facts about second order probabilitiesif one can assert facts in an article on the difficulty of asserting facts about probabilities-is that the court's evaluation of expected cost is $p C$, where $p$ is the mean of the court's judgmental probability distribution. Thus, the criterion of 
expected cost minimization says that the court should impose liability if the mean of its second order probability of toxicity is greater than 0.3.

A satisfactory interpretation of the preponderance test is now close. There is a special probability distribution where the mean is the same as the median. This situation occurs where the distribution is symmetric. Consider the case where $p$ is both the mean and the median of the court's second order probability of teratogenicity. The median has a simple interpretation: half the probability weight of the distribution is to the right of the median and half to the left. When the median is greater than 0.3 it is more likely than not, in the court's judgment, that the probability of teratogenicity is more than 0.3 . This observation suggests a third interpretation of the preponderance test-the court should impose liability when it is more likely than not that the probability of toxicity is greater than $B / C$ (or, in the example, 0.3).

The third interpretation of the preponderance test seems rather natural once the difficulties of the first two interpretations are revealed. This interpretation, however, does not always accord with expected cost minimization. The condition for its consistency with expected cost minimization is that the mean and median of the court's judgmental probability distribution be the same. This condition is satisfied when the court's judgmental probability distribution (its second order distribution) is symmetric.

These observations provide the argument against Posner's Point 4. Under the third interpretation of the preponderance test-the only interpretation admitting consistency with cost minimization-the necessary condition for consistency is equality of mean and median of the court's second order probability distribution, and not equality of error costs.

Conditions under which the third interpretation of the preponderance test provides insufficient incentive for precautionary action can be further specified. Inefficiency in the direction of too much laxness can arise when there is weak evidence of toxicity but when, if there is toxicity, the effects are severe compared with the benefits of the chemical. In other words, the situation may arise in the case of this article, when $B$ is low relative to $C$ and the ratio $B / C$ is relatively close to zero. For the case to be difficult in judgment, the probability of toxicity must be centered somewhere near $B / C$, as in Figure 3(b). If the court has much uncertainty as to its assessment of the probability of toxicity-as a court is likely to have in such cases - the court's judgmental probability distribution is likely to be spread out. The distribution cannot spread far to the left, and the only way it can spread, while still centering around $B / C$, is for it to be skewed to the right, as in Figure 3(b). But in this situation the mean is larger than the median. Thus, the possiblity exists that the court will find that it is more likely than not that the probability of toxicity is less than $B / C$ (and thus find no liability under the third interpretation) though the mean is greater than $B / C$ (so that there should be a finding of liability under the criterion of expected cost minimization). This situation is depicted in Figure 3(b).

The argument so far has been carried forward only in principle. As James and Hazard describe: much of what seems "objective, scientific precision" becomes less 
confining in practice, especially where numerical quantification is not attempted. ${ }^{23}$ The main purpose of the above reasoning is to see how the ideas fit together-or how they do not. If successful, the exercise leads to a "frame of mind" which helps untangle vague, and sometimes erroneous, qualitative arguments.

In practice, the choice is between two cumbersome criteria: (i) impose liability if the court decides that it is more likely than not that the probability of toxicity is greater than $B / C$; or (ii) impose liability if the court finds that the mean of its judgmental probability distribution is greater than $B / C$. The latter is consistent with expected cost minimization, but the former appears a little less cumbersome and a little easier to grasp. What the former loses in principle it may more than make up for in concreteness and implementability. Nonetheless, one may find it useful to remember that the former test tends to a bias toward laxness when the risks are high relative to the benefits. The bias runs the other way when the risks are small relative to the benefits. ${ }^{24}$

The above argument leads to an interpretation of the preponderance test which appears to be at least somewhat different from Posner's. It also leads to conditions (when the interpretation is "economically sound") which are definitely different from Posner's.

In this frame of mind, judgmental probabilities are not "true" or "false"- they are not objective facts in that sense. Instead, the plaintiff's 0.8 probability is her evaluation of the likelihood of toxicity; the defendant's 0.2 is his evaluation; and 0.45 is the court's evaluation based on the arguments brought forward. All three are judgments. When the court comes out closer to the defendant's version of the probability, this does not mean that the defendant's precise number 0.2 has the status of an objective fact which is taken to be "true" or "accurate." Such a result simply means that the court finds the defendant's argument more weighty in the sense that the court's judgment comes out closer to the defendant's than to the plaintiff's. There are, however, some facts. It is a fact that the plaintiff's probability is 0.8 , another that the defendant's evaluation is 0.2 , and a third that the court's judgment is 0.45 . It is also a fact that each of these evaluations is uncertain, and the second order probabilities express these uncertainties.

The difficulties in dealing with uncertain probabilities, or probabilities of probabilities, are real, and it is not surprising that there are occasionally confusions with this subject. This discussion should resolve some of that confusion. The language of second order probabilities, or probabilities of probabilities, is useful in providing a frame of reference and syntax for the various probabilities which appear in legal decisionmaking. Such a language and syntax may prevent such gross confusion as that evidenced by the United States Court of Appeals for the Eighth Circuit in Reserve Mining Co. v. United States. ${ }^{25}$ The circuit court claimed in that case that the lower court had resolved "all" the uncertainties in favor of the

23. F. JAMES \& G. HAZARD, supra note $14, \S 7.11$, at 273.

24. The likely cutoff in bias is where $B / C=1 / 2$.

25. 498 F.2d 1073 (8th Cir. 1979). 
plaintiffs. ${ }^{26}$ To improve matters the circuit court resolved all the uncertainties in favor of the defendant. The language of probabilities provides a means for making decisions consistent with expected cost minimization, without "throwing" the very real uncertainties all to one side or the other.

\section{VI \\ The Ratio of Judicial ERrors}

Posner states "that of the cases decided erroneously, about half will be won by undeserving plaintiffs and about half lost by deserving plaintiffs." 27 However, the numbers of the two types of errors are not in general the same. The ratio of the two types of errors-the ratio of false positives to false negatives-depends on several circumstances. One circumstance is the standard of proof for the similar cases being considered together, $B / C$, while another circumstance is the strength of evidence brought forward.

Consider 1000 cases which are similar to the example in that for each, $B / C=$ 0.3. Suppose that in 300 cases weak evidence of toxicity is brought forward and the court concludes, after weighing arguments from both sides, that the probability of toxicity is only 0.1 . In 500 cases suggestive evidence is brought forward, and the court concludes the probability of toxicity is 0.4 . Finally, in 200 cases strong evidence is brought forward and the court concludes the probability of toxicity is 0.8 .

Under the criterion of expected cost minimization, liability is imposed for the cases where strong and moderate evidence is brought forward (since for these 700 cases $p>0.3$ ), but not for the cases of weak evidence. In the 300 cases for which no liability is imposed, the court expects some false negatives, namely $10 \%$ of the 300 , or 30 false negatives. In the 500 cases where there is suggestive evidence and liability is imposed, there will be some false positives. For these cases the court found only a 0.4 probability of toxicity, or a 0.6 probability of nontoxicity. Thus, the court's expectation is that $60 \%$ of the 500 , or 300 cases, will be false positives. In the 200 cases where strong evidence is brought forward and the court imposes liability, there will be additional false positives. Here the court found 0.8 probability of toxicity, or a 0.2 probability of nontoxicity. Hence the court's expectation of the number of false positives for this group of 200 cases is 40 . Altogether, under the criterion of cost minimization, the court expects 30 false negatives and 340 false positives. The ratio of false positives to false negatives is 340 to 30 , far different from the 1 to 1 ratio posited by Posner. This is the argument against Point 2.

\section{VII}

\section{CONCLUSION}

This discussion suggests, contrary to Posner's analysis, that under a criterion of

26. Id. at 1084 .

27. R. POSNER, supra note 1 , at 432 . 
expected cost minimization, judicial error costs are not in general the same-the number of erroneous judgments favoring undeserving plaintiffs is not likely to be the same as the number of erroneous judgments favoring undeserving defendants, and equality of the two error costs is not a necessary condition for the preponderance test to be "economically sound." In developing such an interpretation of the preponderance test, this article explored three possible interpretations. The first two were rejected as inconsistent with economic efficiency. The third, though not entirely consistent with economic efficiency either, comes much closer than the others. Moreover, when the practical problems of administration are taken into account, this third interpretation of the preponderance test may come closer to minimizing costs than the other operational rules a court might attempt to follow.

One derives the third interpretation of the preponderance test in terms of second order probabilities, or probabilities of probabilities. Under this interpretation, the court finds liability when it decides that it is more likely than not that the probability of toxicity is greater than $B / C$. This interpretation is close to, but not in general quite the same as, the criterion which is consistent with economic efficiency, that is, the court should find liability when it decides that the mean of its second order probability distribution is greater than $B / C$. While this latter criterion will be foreign to many, second order probabilities fortunately resolve themselves into simple first order probabilities. For the court to decide that the mean of its second order probability distribution is greater than $B / C$, it need only decide that the probability of toxicity is greater than $B / C$. The only difference is that with the second order probabilities the court can express its uncertainties in its assessment of the probability of toxicity.

The latter criterion (that the court find liability if it decides that the mean of its second order probability distribution is greater than $B / C$ ) is consistent with economic efficiency, but it is cumbersome. The former criterion (that the court find liability if it decides that it is more likely than not that the probability of toxicity is greater than $B / C$ ) retains the notion of preponderance (the notion of more likely than not), but it is not in principle always consistent with economic efficiency. However, it is easy to state the condition under which it will be consistent. The condition is for the mean and the median of the second order distribution to be the same. In practice they are likely to be close. However, for cases where there are presumed small probabilities of severe harms, there is likely to be some bias toward too little precaution in this interpretation of the preponderance test as compared with economic efficiency. Where there are presumed high probabilities of toxicity but relatively unsevere effects, some bias toward overprecaution will exist.

Once familiar with the language and syntax underlying probabilities of probabilities, it becomes clear that all the discussed interpretations of the preponderance test are stop gaps. When the court becomes familiar with the meaning of the criterion "more likely than not that the probability of toxicity is greater than $B / C$," it may have greater ease in assessing first order probabilities. In doing so, the court can move directly to the criterion "find liability if the probability of toxicity is greater than $B / C$ " while knowing that its assessment of the first order 
probability is, in itself, uncertain. This latter criterion has the advantages of simplicity, consistency with economic efficiency, and direct lineage with the Carroll Towing formula espoused by Judge Learned Hand. 
